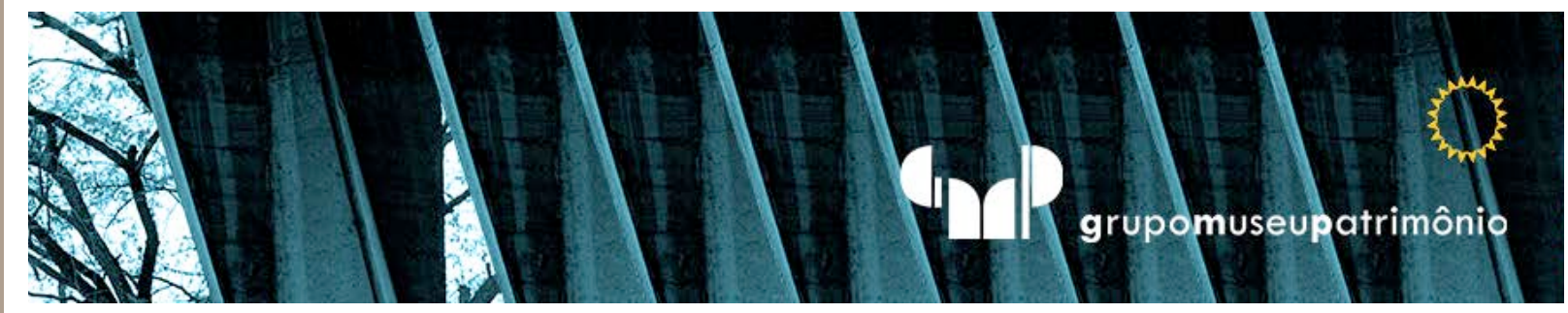

\title{
América Latina em conflito: arte e enunciados
}

\author{
América Latina en conflicto: arte y \\ enunciados
}

\section{Latin America in conflicto: art and statements}

Maria Cecília França Lourenço Professora Titular Sênior. Faculdade de Arquitetura e Urbanismo. Universidade de São Paulo. Líder do Grupo Museu/ Patrimônio. mcfloure@usp.br.São Paulo,Brasil 


\section{Resumo}

Deseja-se indagar a edição e difusão de dada História inscrita em marcos, a fundar sutil escrita. Arte em local projetado labora como uma fábula, a ser vincada em jovens, a par de definir ideologias. Convocam-se artistas para erigir fatos em formas, elevados à categoria - memória/ patrimônio. Por vezes cumprem função delatória ante supressão de dado recente, sendo preciso analisar friç̧ões. Obra no espaço urbano, não raro, fixa-se como única ao transeunte. Então por que vem sendo atacada? Ato simbólico borraria limites entre espaços em conflito?

Palavras-chave: História. Memória. Monumento. Ditadura. Arte.

\section{Resumen}

Investiga-se la edición y difusión de determinada historia hecha en marcos a fundar escritura sutil. Arte local labora como una fábula, que se marcará en los jóvenes, a definir cierta ideología. Invitar a artistas para erigir hechos en formas conquistan la categoría de memoria/patrimonio. A veces se denuncian función de dado reciente, siendo las distinciones de matriz precisos. Trabajar en el espacio urbano como una referencia y fijo se convierte, non raro, en la sólo oportunidad de arte a el andante. ¿Por qué están siendo atacados? ¿Actos simbólicos borrarían límites entre espacios en conflicto?

Palabras clave: Historia. Memoria. Monumento. Dictadura. Arte.

\section{Abstract}

The study want to investigate, editing and dissemination of particularly History entered in mark, found subtle writing. Local art designed working as sort of parable, to be marked in young people, next to define ideology. Invite artists to erect facts in which episodes transform the memory/equity in a special category. Sometimes exert delete function of given recent, being precise analyzing friction. Work in the urban space, not infrequently, as a reference and fixed to the passer-by. So why are being attacked? Does symbolic acts would serve to blur boundaries between spaces in conflict?

Keywords: History. Memory. Monument. Dictatorship. Art. 


\title{
ARTE E INTERPRETAÇÃO
}

\author{
O mundo é coberto de signos que se precisa decifrar, \\ e este signos, que revelam semelhanças $e$ \\ afinidades, não passam, eles próprios, de formas de similitudes. \\ Conhecer será, pois, interpretar: ir da marca visível \\ ao que se diz através dela e, sem ela, \\ permaneceria palavra muda, adormecida das coisas
}

(FoucaultT, 1992 [1970], p. 48)

\footnotetext{
D alavras, sinais, sons, monumentos e murais apontam para semelhanças e afinidades com fatos passados, personagens, datas e tragédias, considerados estes últimos na condição de verdadeiras balizas, aglutinadoras de segmentos locais, regionais, territoriais e, mesmo, internacionais. 0 conjunto exibido temporariamente, ou implantado em espaço de circulação conquista status de memorável e se instala em outros locais, sob a forma de placas, foto, esboço, cabeça ou herma. Assim, nomeiam órgãos públicos e privados e se impõem às crianças, ou no ensino superior, museu, estação
} 
viária, quartel, hospital e não apenas neste Continente Americano. As obras regem discursos com estreitas regras e ordem para tentar representar princípios, unidade, identidade, coesão. Seria então uma operação efetiva para inseri-los nas mentes, ou aposição de um campo ${ }^{1}$ de poder em outro?

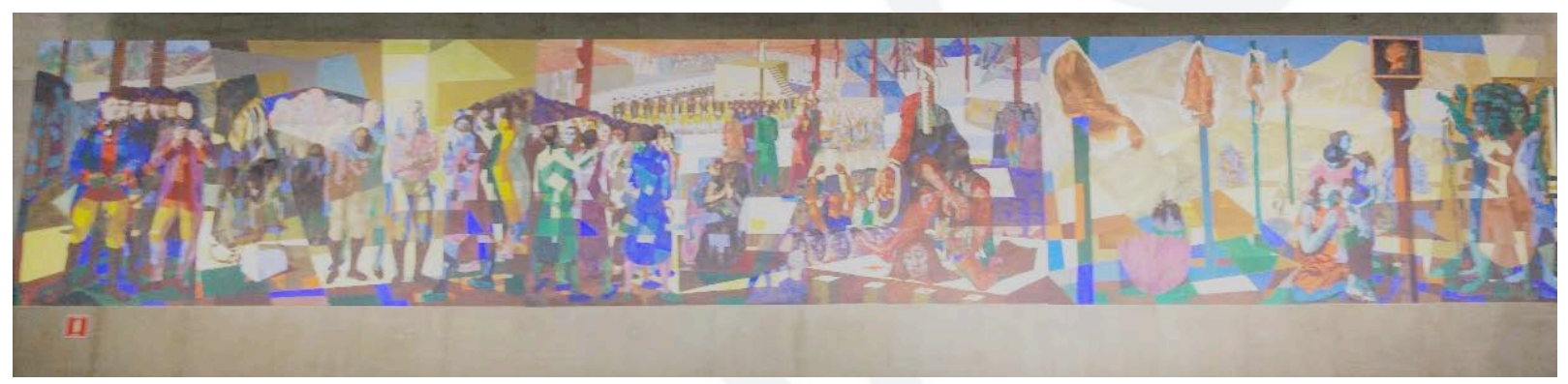

Figura 1 Cândido Portinari. Painel Tiradentes. Memorial da América Latina/ SP. Foto Autora, julho 2017.

Tais formas requerem técnica apurada na criação e realização, mas, além disso, envolvem camadas menos visíveis de enunciação narrativa, por vezes voltada a fomentar valores étnicos, sociais, políticos, profissionais, estéticos, religiosos, ideológicos e, mesmo morais, em disputa e atrito com outros campos em posição contrária, em guerra vazada por palavras, imagens, ódio e temor. Artes em geral exigem algum saber anterior para fruição e, por vezes, elas silenciam o verdadeiro foco, escamoteiam lutas, malgrado possam parecer mero adorno. No entanto gravam posições no tempo e no espaço, que com o decurso de períodos ainda se mantêm latentes e pulsantes, como se verifica ao serem atacadas, nesta época pelo mundo ${ }^{2}$.

As sinuosidades para implantar, manter ou transferir obras celebrativas denotam o bastidor eivado por entrechoque, mesmo ao se selecionar visual atualizado para a época, figurativo ou não, como em memorial datado de 1972

\footnotetext{
${ }^{1}$ Campo aqui alude à tomada de posição extrema e contrária entre partes em luta por princípios e, mesmo, temor. Valem-se de recursos sensíveis, desde som, bordão, literatura, imagem e obra de arte.

${ }^{2}$ Sobre o ataque a monumentos em outras latitudes indico a consulta à edição anterior da Revista ARA.
} 
a ser abordado. Personagens ligadas às ditaduras militares na América Latina vêm gerando atos de repulsa e desnudam como ainda se acham militando os variados lados em surdo e rancoroso litígio. A forte reação confere à criação estatuto de fórum acerca de temas candentes sobre a ocupação urbana, defasagem sociocultural, ato político, populações em exílio, ativismo e arte com finalidade. Assim a expressão a favor ou contrária contribui para desenhar cartografias tortuosas, demarcar rixas, ao lado de disputa nacional em cotejo ao regional e globalizado, ventilando desejo de reversão no quadro atual, tão conturbado nas Américas e nos demais espaços territoriais.

Ao se implantar ou realocar obras em espaço público demanda-se estratégia, ou seja, “[...] o cálculo das relações de forças que se torna possível a partir do momento em que um sujeito de querer e poder é isolável de um 'ambiente'" (De Certeau, 1992, p. 46). Implica, pois, desde reunir condições materiais, conservar e, até, assegurar exposição continuada e em sintonia com pares. Em que pesem os esforços na proposição crítica, obras celebrativas dedicadas a fato ou figuras controvertidos resultam em atitudes extremas: ou, não são erigidas, ou, têm sido alvo de ataque, quando rolam cabeças, geram rito de escracho e deposição simbólica. Seria outro grupo de poder a se valer de contraestratégia?

O Painel Tiradentes de Cândido Portinari (1903-62) ilustra bem os meandros para além da poética. Realizado entre $1948-9$ e inicialmente exposto no Museu de Arte Moderna/SP (1949), a seguir foi instalado em escola privada, denominada Colégio de Cataguases/ MG, em edifício projetado por Oscar Niemeyer (1907-2012), sendo propriedade do escritor Francisco Inácio Peixoto (1908-86). Com o tempo a obra requereu restauro e o preço exigido não seria viável a estes. Então resolveram vendê-la ao governo estadual paulista e não mineiro, como afirmam, apto a arcar com restauro, sendo após acolhido no recém-aberto Memorial da América Latina (1989) (Lourenço, 1999, p. 169). Projeto arquitetônico, obra de Portinari e temática de Tiradentes, ligada à Independência, harmonizaram-se na condição de síntese entre as artes, a ser abordada. 
Outra variável não menos importante quanto acordos, se evidencia na questão de que coleções no espaço urbano, casa ou museu causam o dito esquecimento ativo (Déotte, 1994, p. 26), ao se olvidar origem, destinação, mercado, suavizar conteúdo, forma e estilo. Logo, ao se decifrar, há que se deslocar da fala oficial, pois, estão em jogo outras narrativas e não apenas a subjetivação de artista, curador ou colecionador havendo pacto tácito com o grupo de referência, cuja iniciativa thes deu suporte inicial, moral e/ou financeiro. Observe-se o Monumento às Bandeiras, situado em lugar privilegiado, Parque do Ibirapuera/SP. Erguido por ocasião do IV Centenário da Fundação da Cidade de São Paulo pelo modernista Victor Brecheret (1894-1955). A fruição hoje pouco aduz à exploração de índios e negros ${ }^{3}$ havida em tal episódio. Em que pese toda a enunciação hoje apenas serve a selfie e book de noivas, auferindo títulos prosaicos, entre tantos, Empurra-empurra, Vai-Vai, Deixa-que-eu-empurro.

Com a decretação de início ou fim de época densa, como a ditadura civilmilitar (1964-85), no país, reacende-se posição ideológica oposta, esmaecida com o decurso de tempo. No caso do final do mando de marechais, ao contrário, pululam campos em demanda, em boa parte devido à delonga para se promover diálogo e até abertura de arquivos, entre partes. O Estado nada fez de imediato, para matizar pleito coletivo por democracia versus luta pelo poder de autoridade. Observe-se como a concessão pelos militares da Lei de Anistia (1979), entre nós e ao contrário de outros países da América Latina, agravou-se o descontentamento, a exigir justiça e verdade, diante da verdadeira acomodação de bastidor, sem se enfrentar violação de direitos básicos. Entretanto, subjaz a representação patrimonializadas como memória histórica de tais figuras a gerar hostilidade após quase 30 anos.

Sucedem-se represálias em marcos, monumentos, exigência para mudança em nomes de praças, estradas, ruas, hospitais e em inúmeras instituições, sejam

\footnotetext{
${ }^{3}$ Agradeço a Regina Lara a reflexão compartilhada sobre tal aspecto.
} 
museais ${ }^{4}$ ou educacionais ${ }^{5}$. Algumas iniciativas nasceram na proximidade dos 50 Anos do Golpe (1964) e igualmente por pressão de entidades públicas e grupos organizados para constituição da Comissão da Verdade (2012) em várias latitudes. Em comum também, expunham franca contrariedade ao silêncio e à celebração, a indicar convulsão iminente e cordialidade aparente entre a rua e o quartel. Afinal, estes esboçavam temor ante a extensão de inquéritos policiais, judiciários e financeiros em atuação pública. Pedido de volta de aquartelados desnuda, além de ingenuidade, como a imagem destes foi enquadrada em memória rósea, ao se poupar seus arquivos e ações indeclaráveis, sem abertura dos mesmos e rastro.

\section{ONTEM COMO HOJE REAÇÕES CONTUNDENTES}

Os monumentos são marcos humanos, que os homens criaram como símbolos de seus ideais, objetivos e atos. Sua finalidade é sobreviver ao periodo que lhes deu origem e constituir um legado às gerações futuras. MANIFESTO: "Nove pontos sobre a monumentalidade, uma necessidade humana" Sigfried Giedion, Josep Luís Sert e Fernand Léger (1943) ${ }^{6}$.

Recentes ações para se rever honraria aos tais vultos históricos não são isoladas, pois, com a mudança do Regime em 1889, impôs-se desprezo ao

\footnotetext{
${ }^{4}$ Inúmeras são as casas-museus dedicadas aos indicados ao poder entre 1964-85, embora desde 1960 tenha sido criado o Museu da República voltado a tal finalidade. Vale relembrar a musealização efetuada com mandatários, no período 1964-85: Humberto Castelo Branco (19657), Museu e Biblioteca no quartel da cidade de Santa Rosa/RS, Mausoléu em Fortaleza/CE, aberto em 1972; Artur da Costa e Silva/casa-museu em Taquari/RS (1985), recentemente o vulto em praça da cidade foi derrubado e remetido à casa museu, com controvérsias, idas e vindas partidárias; Emílio Garrastazu Médici (1969-74), em sua cidade natal o Museu Dom Diogo de Souza/Bagé/RS exibe uma sala ao general, com exposição de fardamentos e objetos de uso pessoal; Ernesto Geisel (1974-9), acervo doado pela família ao Museu da Justiça Militar da União; e João Figueiredo (1979-1985) teve parte de seus bens leiloada pela família em 2001. O Instituto do Patrimônio Histórico e Artístico Nacional tentou embargar, já que o acervo foi presenteado ao presidente e não à pessoa com vistas a enviar parte ao Museu da República/RJ, sem sucesso.

${ }^{5}$ Conforme se divulgou nos jornais O Globo e Folha de S. Paulo, baseados no Censo Escolar 2012, entre as 3.135 unidades escolares públicas que homenageiam ex-chefes da República, 976 pertencem aos cinco generais que comandaram o regime militar.

${ }^{6}$ O Manifesto por ser muito extenso não foi publicado e, em 1944, Giedion cedeu sua parte para coletânea organizada por Paul Zukker, como relembrou em vários depoimentos.
} 
Imperador, que teve bens leiloados, no lugar de distribuí-los a entidades preservacionistas, ato indicativo de valor. Na verdade foram convertidos em mercadoria venal, a incluir louça, cristal, vestimenta, arma, mobiliário e obras de arte, adquiridos pelas famílias, que antes apoiaram a Casa Imperial lusa. Além disto, logradouros denominados por Rua, Praça ou Avenida do Imperador similarmente tiveram designação demudada, ganhando nomes como - República, Liberdade, Marechal Deodoro, 15 de Novembro, entre outros constrangimentos impostos ${ }^{7}$.

Se antes cabiam homenagens ao soberano, entes religiosos, heróis e citação de passado idílicos, no século passado a mobilização adveio de outras coligações na obtenção de recursos, causas, marco temporal e coesão diferencial de dado grupo, denotativos de campos em litígio. Murais, relevos, textos, esculturas já alocadas e de várias poéticas pouco sensibilizaram decorrido tempo e então andam, passeiam, foram implodidas e, muitas vezes, também permanecem no papel, a não ser que comunidades emergentes as salvem do sombreamento de mapotecas e ruínas. Vale citar o monumento criado por Oscar Niemeyer - Arco da Maldade.

A comovente obra seria erigida em frente ao Morro da Viúva/ RJ, a pedido do Grupo Tortura Nunca Mais, em 1986. Arguta seria constituída por linha encurvada, similar a uma flecha, a conter na extremidade suspensa, humano, desumanizado. Por que jamais foi edificada, como também aquele destinado a homenagear Simon Bolívar (2007) no alto do Monte El Ávila em Caracas/Venezuela? Entre as hipóteses se encontram alguns aspectos a sinalizar a força de formas projetadas a escancarar condenação, crítica e desacordo com o lugar-comum, cuja organização espacial, nos dois citados episódios transformaria um espaço vivenciado em lugar distinto, a exigir interpretação para além das formas geométricas.

\footnotetext{
${ }^{7}$ Entre tantos nomes alterados mencionem-se as atuais cidades: Campinas/SP, Curitiba/PR, Itu/SP, Manaus/AM, Ouro Preto/MG, Petrópolis/RJ, Porto Alegre/RS, Recife/PE, São Paulo/SP, Sorocaba/SP.
} 
Em Caracas a sutileza projetada por Niemeyer para monumento, com formas geométricas talvez se distanciasse da grandeza pretendida por Hugo Chávez, porquanto este buscou associar-se a aquela figura histórica, líder de Independência, em vários países da América Latina ${ }^{8}$. Já o esboço do Arco da Maldade traria referências indesejáveis e não apenas pelo conteúdo, uma vez que o arquiteto neste escancarou situação trágica e apartada do pacto entre lados em confronto, a desvelar espaços em conflito. Além disso, ousou ao desafiar postulados modernos, entre os quais a autonomia da arte, sem se afastar de aspectos construtivistas; no lugar de esperada inovação, preferiu premissa cara no entre guerras, de aproximação entre as artes, a chamada integração das artes e/ou síntese das artes, seja na face francesa, com Le Corbusier (1887-1965), seja na alemã de Walter Gropius (1883-1969) ${ }^{9}$.

Artistas, historiadores, críticos, arquitetos, paisagistas e urbanistas militaram em importantes fóruns e com motivo forte para refluir a consecução de obra a mimetizar fatos em local público, desde o moderno. Entre as justificativas, se considerem: 1) contestação de redução de obras à condição de mera ilustração direta de tema por meio de alegorias; 2) demanda por prestígio para movimentos nacionalistas e em busca por identidade republicana, contrários ao transplante de tradição europeia, impostas como fetiche de um passado notável; 3) valorização da recepção para público urbano de diferentes camadas sociais com prevalência de soluções a colocar o espectador como centro e não mais, mero figurante extasiado; 4) vínculo ideológico entre arte e efemérides

\footnotetext{
${ }^{8}$ Bolívar constitui-se em figura central na Independência da Bolívia, Colômbia, Equador, Panamá, Peru e Venezuela. Assim, Chávez preferiu para honrá-lo artista figurativo e venezuelano, de aceitação mais direta pela população, Alejandro Colina (1901-76), com projeto de escultura equestre, antes proposto, como amplamente noticiado (2007).

${ }^{9}$ Vale assinalar que Le Corbusier e Gropius erigiram esculturas, a citar a Mão Aberta na nova capital de Punjabi, em Chandergarh, Índia, do franco-suíço e a criação do diretor da Bauhaus, vencedor de concurso para Monumento aos Mortos (1920-2) em memória das vítimas em massacre em Berlim. Este foi destruído em 1936, considerado na pecha de arte degenerada dentro da política discriminatória proposta por Adolf Hitler e reconstruído em 1946.
} 
criadas pelo poder, que estão subjacentes ao Manifesto denominado Nove pontos sobre a monumentalidade, uma necessidade humana ${ }^{10}$.

Desde os anos 1930, na Europa, simpósios com variado espectro de criadores produziram debates e manifestos direcionados a garantir a monumentalidade das cidades e tornar a arte moderna uma cultura à disposição da plateia urbana, ainda habituada às alegorias equestres e piramidais. Os modernistas uniram a este intento o pleito por aglutinar várias artes no que se convencionou nomear arte total, desde as proposições de Richard Wagner relativa à ópera, em busca de uma grandeza distinta. Programaram-se encontros com realce à série designada, Congresso Internacional de Arquitetura Moderna (Ciam), a coligar criadores, entre tantos, Le Corbusier (1997-1965) e Walter Gropius; Sigfried Giedion (1888-1968), Fernand Léger (1881-1965), Josep Sert (1902-63) e outros brasileiros, também comprometidos com os conceitos.

Em célebre texto de 1936, ano da segunda vinda ao país, Le Corbusier distinguiu contribuições chamando a atenção para o tipo de implantação escultórica desejável, naquilo que indicou por "Lugares porta-vozes, portapalavras, alto-falantes. Entra aqui o escultor, se vale a pena sustentar o discurso" (Lourenço, 1995, p. 263) ${ }^{11}$. Especifica então a exigência em dar voz a esta modalidade e reitere-se, amparar discurso coeso do escultor, com clara sinalização de uma consistência com o que entendia por pureza e clareza, a gerar, como alude, insigne presença com dada obra de arte, ou seja, linguagem coetânea a seu tempo, logo apartada do passado e embasada em causas.

\footnotetext{
${ }^{10}$ Trata-se de tema até então inédito, que compôs minha tese de doutorado, editada sob o título "Operários da modernidade".

${ }^{11}$ Durante a construção do designado à época por Ministério da Educação e Saúde Pública sucederam-se debates sobre a utilização ou não de esculturas e murais. Le Corbusier valeu-se de todos os argumentos, desde a citação do passado luso, a justificar o emprego de murais em azulejos, à consecução de termos incisivos para demonstrar a conveniência em se adotar a terminologia citada.
} 
Note-se que culturas nativas nas Américas e a escultura em vários tempos convergiram no uso da forma em monumentos, na raiz indo-europeia do termo a agregar, mens, mente, menção, memória; mais monere, ensinar, sinalizar e alertar. Então a feição moderna defendida ao lado da linguagem construtiva tributaria, no futuro, questões cáusticas ao presente e, também, lograria ao conjunto urbano, certa monumentalidade. Estes fatores se encontram na base da razão pela qual muito se defenderá aquela obra, que se reporte à memória coletiva, social e de grupos espoliados, no dizer de Giedion, Léger e Sert, no referido Manifesto.

A diferenciação entre integração e síntese se operaria na questão: obras de arte seriam regidas pela arquitetura ou se uniriam como partícipes desde o início para cunhar a potência imanente do moderno? De fato isto incidiu mais com arquitetura, mural e/ou painel, planejamento urbano, paisagístico, menos com esculturas. Ponto fulcral do moderno brasileiro deu-se durante a Ditadura Vargas com apelo populista a exigir arte figurativa e lamentavelmente sujeita à censura em órgãos específicos. Vale assinalar que nesta como nas demais, institui-se o Departamento de Imprensa e Propaganda/ DIP (1939) para documentar, controlar e punir ideias, tidos como fora do lugar. Após o Golpe (1964) novamente foi gerado tal freio, passando a controlar civis, militares, órgãos públicos e privados.

Não se imagine trato singular no campo da educação, durante a Ditadura civilmilitar, embora o discurso oficial tentasse passar uma visão renovada, mas no fundo pensava-se que caberia à escola, estritamente, transmitir saber levá-lo a conquistar profissão, em universidades. Por reunir nestas forte resistência à ausência de democracia, logo se criou órgão de controle vinculado à Reitoria em cada unidade, chamado Assessoria Especial de Segurança e Informação/ $A E S I{ }^{12}$. Estes órgãos forneciam informações, triagem ideológica de

\footnotetext{
${ }^{12}$ Diversos comitês nos estados, reunidos sob a designação Comissão da Verdade/ CV expuseram como desde a Portaria MEC № 12, de 13 de janeiro de 1971 tais instituições originaram setores, inicialmente denominados Assessoria de Segurança e Investigação/ ASI, depois unificados na designação Assessoria Especial de Segurança e Informação/ AESI. Como
} 
contratados e candidatos, documentação, delação, colaboração irrestrita, além de também terem preenchido quadros para ministério, secretarias estaduais, municipais e também em nomeação de executivo, como prefeitos, governadores, os ditos biônicos, a incluir banqueiros, industriais e políticos, indicados pelo poder central.

\section{DESMONUMENTAR: RASTROS E INTERDITOS}

$O$ rastro é a aparição de uma proximidade, por mais longínquo que esteja aquilo que o deixou. A aura é a aparição de algo longínquo, por mais próximo que esteja aquilo que a evoca. No rastro, apoderamo-nos da coisa; na aura, ela se apodera de nós (Benjamin, 1994, p. 170)

A manifestação artística pode exercer papel digno ao desvendar meandro soturno, ilação indeclarável e escancarar atuação distinta em se memorializar e julgar responsáveis por crime de estado ${ }^{13}$, seja em filme, literatura, teatro ou artes em geral. Posições ditatoriais em diversos países vêm gerando reações, desde parentes de vítimas até jovens ativistas. Há ações para retirar de via pública nomes de rua, escola, hospital, entre outros ${ }^{14}$ e também para

tem sido divulgado, na USP, AESI foi ativa entre 23 de maio de 1973, ao final da gestão do Reitor Miguel Reale Jr., autodesignado por integralista, sucedido por seu vice, Orlando Marques de Paiva (1973-7) e logo após a morte do estudante Alexandre Vannucchi Leme (1950-73). Apenas em 1982, o Reitor Hélio Guerra dissolveu já ao tomar a posse. As relações com a repressão eram tão incestuosas que na data de criação, a Reitoria ofíciou o fato ao Departamento de Informação e Segurança/ DIS no Ministério da Educação, ao Centro de Informações e Segurança da Aeronáutica/Cisa, ao Centro de Informações da Marinha/Cenimar, Polícia Federal, ao Serviço Nacional de Informação/SNI e ao Destacamento de Operações de Informação - Centro de Operações de Defesa Interna/Doi-Codi. Também na gestão de Paiva, em que foram mortos vários membros da USP, o setor ordenava aos diretores para e evitar simpósios estudantis, em papel timbrado do Gabinete do Reitor/USP. Diversas CV desvelaram estratégia similar em outras entidades, talvez enquadradas por oportunismo, medo ou subserviência de alunos, docentes, funcionários, diretores e chefes.

\footnotetext{
${ }^{13}$ Argentina tem sido referencial ao condenar o ditador Jorge Rafael Videla à prisão perpétua, com idade avançada, em que morreu em 2013, não parando por aí. No último 29 de julho (2017), em Mendoza mais quatro juízes federais foram julgados e condenados por promover impunidade em sequestros, torturas, assassinatos e omissão em investigação, com ampla divulgação em mídias.

${ }^{14}$ Em 16 de outubro de 2017, na semana em que se analisará a segunda denúncia contra o vice em exercício Michel Temer e ministros, além de votar sobre o afastamento de Aécio Neves por
} 
achincalhar figuras enredadas com repressão, ou como se consagrou na Argentina, Desmonumentar ${ }^{15}$, quando obra promove personagens envolvidas em frontal desrespeito à vida e à alteridade fundada em valores estranhos ao de quem exerce poder.

As artes em geral também se mostraram atentas ao falso discurso de Ordem e Progresso propalado durante o Golpe Militar. Bordões em grande parte difundidos no esporte mais popular, o futebol, indicam diferença entre realidade e discurso pretendido: Milagre econômico; Ninguém segura este país; Brasil: ame-o ou deixe-o; Integração nacional; Para Frente Brasil; além de - Infiltração comunista, A soldo de Moscou, Terrorista e Subversivo ${ }^{16}$. Com a abertura de arquivos estadunidenses corroborou-se outro cenário subjacente, contra o qual tantos lutaram, ou seja, total comando, treinamento e colaboração militar em ações de repressão pelos Estados Unidos, junto aos países na América Latina dentro da Guerra Fria, por temor de que a Revolução Cubana se estendesse pelos vizinhos.

Marc Augé em seu estudo Les formes de oublie trabalha com o sentido de três palavras a merecer considerações para se aprofundar razões sobre o ativismo atual voltado a desmonumentar, ou descelebrar, com a intenção de evitar perdão e indiferença, garantir múltiplas lembranças e enfrentar corte abrupto de vidas na acepção de direito à memória. Augé distingue então: A) Oubli (esquecimento); B) mémoire (memória); e C) souvenir (lembrança). A cada uma

receber o que a Justiça alega ser propina, placa para identificar Câmara dos Deputas em Brasília foi sobreposta e adesivada com a mesma família de letra e cor tendo o texto: Formação de quadrilha. Corrupção Ativa. O grande acordo nacional.

${ }^{15}$ Sob esse lema Desmonumentar há na Argentina ações inicialmente lideradas pelo escritor, professor e jornalista Osvaldo Jorge Bayer que desde 2004 luta para alterar celebrações, nome de logradouros do país, a incluir o monumento em Buenos Aires a Júlio Argentino Roca, militar com ações trágicas aos povos tradicionais e originários.

${ }^{16}$ A definição de subversivo merece interesse no Artigo 1․․ do Decreto no 447, de 28 fev. 1969, ao elencar atos de ontem, hoje e, talvez, amanhã: "organizar paralizações das atividades escolares ou participar delas; atentar como pessoas ou prédios das instituições; participar de desfiles ou passeatas sem autorização; confeccionar, imprimir, distribuir ou guardar material gráfico sem autorização; sequestrar ou manter em cárcere membros da instituição de ensino; utilizar o espaço da universidade 'para fins de subversão' ou 'praticar ato contrário à moral e à ordem pública"”. 
associa palavras capazes de aprofundar a violência, ao se privar alguém do direito à memória, a saber: A) pardon (perdão)/ indifférence (indiferença)/ négligence (negligência); B) remords (remorso)/ obsession (obsessão)/ rancune (rancor); C): vie (vida)/ mort (morte) (Augé, 1998, p. 19). Na América Latina, aos poucos vem causando repulsão, não retaliação, mas sim, com o foco de chamar a atenção, para memórias ceifadas, visando que não se repitam tal intolerância. Seria diferente se não se impedisse a permanência de rastros e resíduos no tecido urbano sobre personagens com ideais democráticos e se discutisse sobre manter ou não a memorialização de ações truculentas contra opositores, em franco desvio na função de estado e, mesmo, em conluios entre nações?

Desvelando trânsito entre ditaduras na América Latina, a união deflagrou outra fonte violenta, a dita Operação Condor com troca de informaç̧ões, arquivos, documentos e estratégias para eliminar resistentes à falta de democracia e clamando por liberdade ideológica, em tese sem deixar rastro. $\mathrm{O}$ tratamento vil se cotejado ao humanismo, vem sendo alvo de reflexão em variados setores. Afinal ali se perdeu a tal dimensão, que nos diferencia de outros seres vivos, em espacial quando se pensam, como agora, em soluções escapistas e abomináveis para a grave crise em todos os quadrantes em variados territórios. As inquietações foram decisivas para reunir material documental sobre a Operação Condor, formada pela junção entre Argentina, Bolívia, Brasil, Chile, Paraguai e Uruguai com apoio dos Estados Unidos, na década de 1970, em plena Guerra Fria.

Celeumas vêm colaborando para chamuscar o engodo e a impunidade, entre as quais: A) em plena censura, corpos atirados no Rio da Prata emergiram (1976). B) em 1992 o paraguaio, ativista, Martín Almada recebeu um informe sobre dados abandonados, que incluíam a Operação Condor, ele, também supliciado, e que tentava obter informes sobre o sumiço de sua mulher. D) revogação sucessiva de sigilo em documentos nos Estados Unidos, desde o Governo Clinton (1993-2001). E) iniciativa na Argentina em revogar anistia a torturadores (2003). Felizmente jovens pesquisadores em todos os países vêm 
se interessando pelo tema para investigação acadêmica, com análises baseadas em farto material documental ${ }^{17}$.

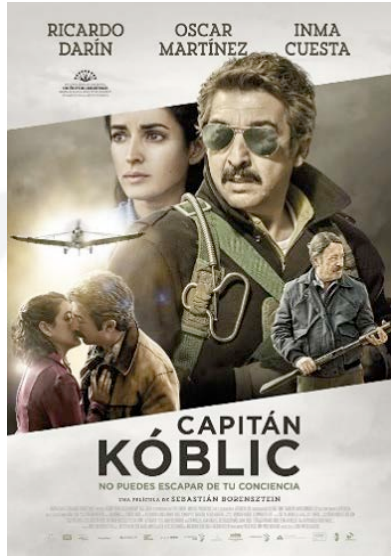

Figura 2 Cartaz de Kóblic (2016). Fonte: http://m.imdb.com/title/tt5462400/

Livros importantes já foram editados ${ }^{18}$ e há pouco, a malfadada Operação Condor ou Carcará no Brasil foi revisitada como sutil pano de fundo no filme Kóblic (2016). Nele o diretor Sebastián Borensztein (1963) expôs subsídios consideráveis para se analisá-la, valendo-se de suposto aviador Tomás Kóblic tentando negligenciar o passado, em que esteve ligado ao terrorismo de estado em seu país, Argentina. Ricardo Darín (1957) representa Kóblic, experiente e obsessivo em levar uma vida sem lembranças, na ficcional Colônia Elena, tentando apartar-se de quando fora piloto de avião, designado para jogar opositores do regime militar no Rio da Prata com pedras amarradas nas pernas. Outra série de filmes por toda América Latina, a incluir Brasil, enfrentou a tarefa graças às pesquisas em livros sobre tal período infausto ${ }^{19}$.

\footnotetext{
${ }^{17}$ Consultar alguns entre os títulos de teses e dissertações sobre Operação Condor anexados na Bibliografia.

${ }^{18}$ Material ímpar em livro foi editado em seminários e reunidos por, Lucas Figueiredo, Rossano Lopes Bastos, John Dinges e, também, Associação dos Docentes da USP e pelo jornalista Luiz Cláudio Cunha.

${ }^{19}$ Entre os filmes: Em Que Bom te Ver Viva (Brasil, 1989), direção de Lúcia Murat, ela mesma presa e que entrevista mulheres; Operação Condor (Brasil, 2007), de Roberto Mader; Cidadão Boilesen (Brasil, 2009), dirigido por Chaim Litewski, e trata de alto executivo da Ultragás, que financiou e gostava de presenciar tortura; Advogados Contra a Ditadura (2014) de Silvio Tendler,
} 
Todas estas soturnas repressões e visando pressionar a nomeação da Comissão da Verdade/ CV, organizaram-se ações por todo país baseadas nos coletivos Escraches Populares, na Argentina, Uruguai e o Funas ${ }^{20}$, do Chile, relacionando-se com estes e denominando-se também por H.I.J.O.S. ${ }^{21}$. Obtiveram em muitos estados brasileiros a formação da CV e seguem sendo concretizados outros ${ }^{22}$, por coletivos, desde 2012. Neste ano seis escrachos a repressores incidiram em seis cidades simultaneamente, a 26 de março, organizados pelo Levante Popular da Juventude/ LPJ. No Rio de Janeiro, programou-se passeata exigindo alteração de nomes de militares, torturadores e civis envolvidos, e se encerrou com faixas e palavra de ordem no Monumento ao Marechal Castelo Branco, próximo ao Forte Duque de Caxias, no Leme ${ }^{23}$.

Torturadores, legistas e policiais igualmente foram expostos e, em 7 de abril de 2012, na proximidade da Rua Zapará 61/ Vila Madalena/SP, ação organizado pelo Movimento Verdade e Justiça pelo bairro, terminou nesse endereço, casa do médico legista Harry Shibata, depositando-se flores e cartazes na frente da casa. Espalharam-se cartazes alusivos aos laudos por ele expedidos, posteriormente classificados como falsos, embora já houvesse evidências em contrário. Entre tantas, as mensagens denunciavam: Alerta vizinhos! Em seu

expõe jovens advogados a tentar salvar detidos. Sobre a ditadura no Chile (1973-1990), entre tantos de Patricio Guzmán, cito o recente sobre os atirados no mar O Botão de Pérola (2016). Proibido Pisar nas Flores (2009), de Luis González Zaffaroni, exibe a resistência estudantil no Uruguai (1973-84). Sobre a ditadura boliviana (1964-82), Olvidados (2014), de Carla Ortíz. Acerca da ditadura Alberto Stroessner, Paraguai (1954-89), Cuchillo de Palo (2010), cineasta paraguaia Renate Costa, a abordar perseguição a homossexuais, nesse período.

${ }^{20}$ Funas, na língua dos Mapuches, originários da Patagônia chilena significa podre.

${ }^{21}$ Em 30 de abril de 1995 em Córdoba/ARG reuniram-se filhos de desaparecidos, mortos, exilados e presos políticos da ditadura para formara organização H.I.J.O.S. (Hijos por la Identidad y la Justicia, contra el Olvido y el Silencio). Propuseram-se a reivindicar la lucha de nuestros padres y sus compañeros, buscar a nuestros hermanos apropiados, luchar contra la impunidad. Desde então fizeram atos públicos e disseminam a outros, a tática de denúncia contra a impunidade.

${ }^{22}$ Em 21 de abril de 2016 na casa do vice Michel Temer, Alto de Pinheiros/SP, enquanto este recebia aliados para destituir a presidente Dilma Rousseff, foi surpreendido pelo Escracho programado por membros do Levante Popular da Juventude/LPJ, como se noticiou.

${ }^{23}$ No Palácio da Abolição em Fortaleza, Ceará (2011), o argentino Marcelo Brodsky (1954), com apoio da Associação 64/68 Anistia e do Instituto Frei Tito, fez ação em volta do lago com música de Tenorinho, vítima da Operação Condor. 
bairro morra Harry Shibata o médico legista da ditadura militar... Sônia Maria de Moraes Angel Jones. Desaparecida política. Shibata atestou morte por tiroteio...; Vladimir Herzog: morto sob tortura. Harry Shibata declarou-o suicida sem ter visto o corpo, entre outras.

A pressão se deve em grande parte também ao fato de, decorridos vinte e sete anos desde o término oficial da ditadura (1985), sem falar na assinatura da Anistia (1979), o Estado lentamente começou a enfrentar a cicatriz, com política pública para restituir o que seria a verdade dos fatos (2012), ao lado de programa para se erigir monumentos (2004) a Pessoas Imprescindíveis. Na cidade de São Paulo a Comissão Estadual da Verdade e a dos Familiares de Mortos e Desaparecidos Políticos mobilizaram-se para a troca de nomes de atuantes na Ditadura civil-militar. Desde uma extensa lista apenas dois logradouros tiveram seus nomes trocados ${ }^{24}$. Em direção oposta outros tentam manter os rastros, como se observa em informes, reiterando campos em conflito. Idas e vindas são constatadas em vários países, como noticiou a imprensa estadunidense, uma escola com nome de dirigente da Ku Klux Klan, a bradar por racismo, foi trocado, ante a pressão de moradores.

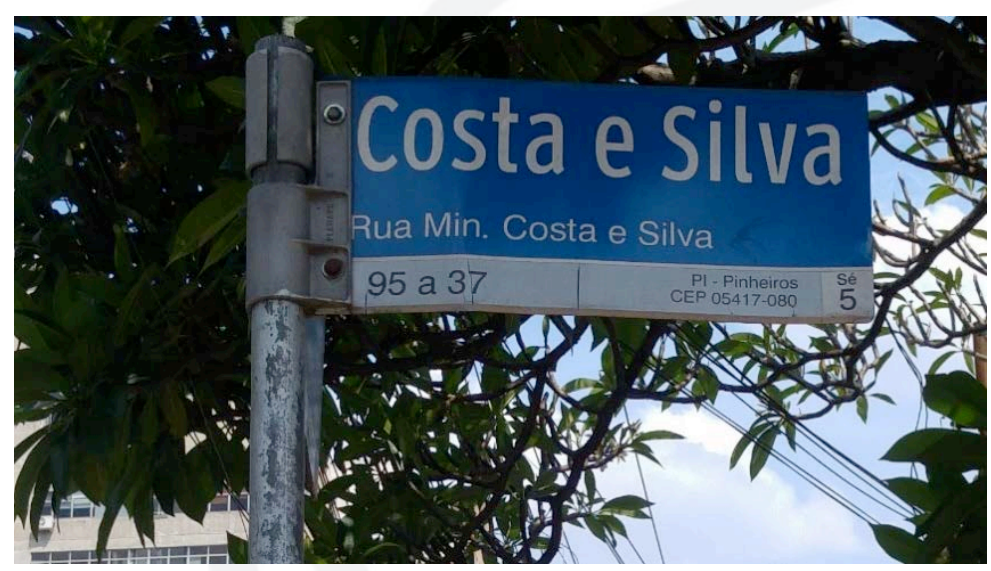

Figura 3 Rua Min. Costa e Silva/SP. Foto autora, 11 de outubro, 2017.

\footnotetext{
${ }^{24}$ Sensibilizaram políticos e, assim, o Elevado Costa e Silva, via de ligação Leste/Oeste, apelidada de Minhocão, passou a Elevado João Goulart (2016); também a Av. Golbery do Couto e Silva, auxiliar direto de Castelo, Giuseppe Benito Pegoraro, atuante na resistência ao regime, naquela região.
} 
Iniciaram-se ações e, entre inúmeras, vale assinalar a sequência de embates com as figurações de Humberto de Alencar Castelo Branco, coordenador e primeiro mandatário do Golpe. Em Fortaleza/CE após a morte ${ }^{25}$ em situação não suficientemente esclarecida, o arquiteto Sérgio Bernardes projetou o Mausoléu, com forma em balanço e dentro de premissas modernistas, por ironia na Praça da Abolição, antiga sede do Governo do Estado, para abrigar restos mortais de Castelo e de sua mulher, inaugurado em 1972 por seu sucessor, Emílio Garrastazu Médici, alvo frequente de protestos. Ao se iniciar o trabalho da Comissão da Verdade naquele estado o coletivo Aparecidos Políticos ${ }^{26}$ propôs uma ocupação em 5 de dezembro de 2012, data de morte de Carlos Maringhella (1911-69), líder da Aliança Libertadora Nacional, organização de oposição à ditadura, com projeções e poesias, no local.

Igualmente Castelo teve outra homenagem, após a morte, em Porto Alegre/RS de um monumento inicialmente solicitado aos significativos escultores Francisco Stockinger (1919-2009) e Vasco Prado (1914-2009), que negaram a encomenda, porém aceita por escultor, Carlos Tenius (1939). Em 1974 recebera outra, Monumento aos Açorianos, referencial para a cidade. No caso daquela ao Marechal, tudo já estava acertado com financiamento de Federação das Indústrias, Federação da Agricultura, Federação das Associações Comerciais do RS, em 1977. Em 2014 uma faixa foi colocada: Ditadura Nunca Mais. Outras ações densas sucederam, como na cidade mineira de Dom Cavati em que o prefeito cancelou a homenagem e mandou derrubar busto existente ${ }^{27}$.

\footnotetext{
${ }^{25}$ O Marechal retomava da fazenda de sua amiga, a escritora, Rachel de Queiroz (1910-2003) e no local em que o avião chocou no solo resolveu-se em 1983, demarca-lo com mármore em homenagem às vítimas, então denominado, Marco-zero. Afastado pouco se conservou da placa, em 2014 trabalhadores de uma barragem removeram-na e o encarregado da obra alegou desconhecê-la.

${ }^{26}$ Agradeço ao mestrando Eduardo Bruno Fernandes Freitas pela informação.

${ }^{27}$ Em 2014, o LPJ projetou várias atos em parceria com outros, em função dos 50 anos do Golpe; cito Londrina/PR, busto de Castelo recebeu a palavra - Ditador; Ipatinga/MG, propunha-se a troca deste para o de José Elias dos Santos, um entre os operários da Usiminas vítima do massacre (1853), assim como retirada do busto do Marechal situado na Praça 1o de Maio.
} 
Considere-se igualmente a alteração de nome de unidades educacionais: apenas no Maranhão, por força de lei, várias delas substituíram o nome de Marechal Castelo Branco, como na capital passou a ser chamada de Unidade Jackson Kleber Lago, em homenagem ao ex-governador do Maranhão, morto nesse ano; em Imperatriz/MA, o antigo Centro de Ensino Castelo Branco passou a homenagear Vinícius de Moraes; nos municípios de Caxias, Fortaleza dos Nogueiras e Governador Newton Bello também no Maranhão foram trocados por Professores Suely Reis, Vera Lúcia dos Santos Carvalho e Antônio Macêdo de Almeida, respectivamente. Na Bahia, Bairro de Peri Peri/Salvador, o Colégio Estadual Presidente Humberto de Alencar Castelo Branco, por meio de consulta da comunidade envolvida preferiu "Madiba" Nelson Mandela. Em Vitória/ ES, a sala de reuniões de conselhos superiores na Universidade Federal, antes, ainda com homenagem ao Marechal, mudou-se para lembrar o de estudantes perseguidos por lutar contra o regime militar.

Como se nota o dever de memória em casos traumáticos cada vez mais se revela disputa de poder entre espaços em conflito, indo além de questões estéticas, na tentativa de revisão histórica e por não aceitar memória edulcorada. Hoje e ao redor de continentes vem assumindo também a condição de pauta forçosa para colocar à luz fatos calados e agora acareados com realidades antes esmaecidas e, mesmo, ante luto familiar. As distintas religiões há muito intuíram a força de acuradas imagens, palavras, símbolos e sons para culto, devoção e sujeição. Não obstante com a sucessão de grupos, novos desvios, acidentes e vielas vêm emergindo, a demandar representação renovada e obsolescência das anteriores. Modificam-se as enunciações e, em parte, graças às novas gerações, em contrapartida, permanece a capacidade de interpretar formas para desvelar campos em conflito.

Ciça, Primavera 2017. 


\section{REFERÊNCIAS BIBLIOGRÁFICAS}

\section{Publicações}

Augé, Marc. Les formes de l’oublie. Paris, Payot \& Rivages, 1998.

Bastos, Rossano Lopes. Uma arqueologia dos desaparecidos: identidades vulneráveis e memórias partidas. São Paulo, Iphan/SP, 2010.

Benjamin, Walter. A obra de arte na era de sua reprodutibilidade técnica In: Obras escolhidas: Magia e técnica, arte e política. 6 ed. São Paulo: Brasiliense, 1994.

Cunha, Luiz Cláudio. Um sequestro de uruguaios no Brasil: uma reportagem dos tempos da ditadura. Porto Alegre, L\&PM, 2008.

De Certeau, Michel. A invenção do cotidiano: 1- artes de fazer 4 ed. Petrópolis: Vozes, 1992.

Déotte, Jean-Louis. Oubliez! Les Ruines, L'Europe, Le Musée, Paris: L'Harmattan, 1994.

Dinges, John. Os anos do Condor: Uma década de terrorismo internacional no Cone Sul. São Paulo: Cia das Letras, 2005.

The Condors Year: How Pinochet and his allies brought terrorism to three Continents. Nova lorque: New Press, 2004

Figueiredo, Lucas. Olho por olho: os livros secretos da ditadura. Rio de Janeiro: Record, 2009.

Foucault, Michel. As palavras e as coisas: Uma arqueologia das ciências humanas. São Paulo, Martins Fontes 1992.

Giedion, S. Arquitetura e comunidade. Lisboa, livros do Brasil, s.d.

Lourenço, Maria Cecília França. Museus acolhem moderno. São Paulo: Hucitec, 1999.

Operários da modernidade. São Paulo: Hucitec/ Edusp, 1995.

O CONTROLE ideológico na Usp: 1964-1978. São Paulo: Adusp, 2004.

\section{Trabalhos acadêmicos sobre Operação Condor}

Braga, Leonardo Marmontel. A internacionalização do terror: o caso argentino. Porto Alegre: UFRGS, 2012 (Tese de doutorado). 
Cassol, Gissele. Prisão e tortura em terra estrangeira: a colaboração repressiva entre Brasil e Uruguai (1964-1985). 119 f. Santa Maria/RS: UFSM, 2008. (Dissertação de mestrado).

Cerveira, Neuza Maria Romanzini Pires. Memória da dor: a Operação Condor no Brasil (1973-1985). São Paulo HS/USP, 2005. (Tese de doutorado).

Escaliante, Elizabete Aparecida. Políticas coercitivas da Operação Condor. São Paulo: PUC, 2010 (Dissertação de mestrado).

Fernandes, Ananda Simões. Quando o inimigo ultrapassa a fronteira: as conexões repressivas entre a ditadura civil-militar brasileira e o Uruguai (1964-1973). Porto Alegre: UFRGS, 2009. (Dissertação de mestrado).

Fernandez, Jorge C. Anclaos en Brasil: a presença argentina no Rio Grande do Sul (1966-1989). Porto Alegre: UFRGS, 2011 (Tese de doutorado)

Silva, Jussaramar da. A Usina de Itaipu e a Operação Condor: o outro lado das relações bilaterais Brasil- Paraguai (1973-87). São Paulo: PUC, 2006 (Dissertação de mestrado).

Mariano, Nilson Cezar. Montoneros no Brasil: terrorismo de estado no sequestro-desaparecimento de seis guerrilheiros argentinos. Porto Alegre: PUC, 2006. (Dissertação de mestrado).

Motta, Rodrigo Patto Sá. Em guarda contra o perigo vermelho. São Paulo: Perspectiva/Fapesp, 2002.

Padros, Enrique Serra. Como el Uruguay no hay: terror de estado e segurança nacional. Uruguai (1968-1985); do pachecat à ditadura civil-militar. Porto Alegre: PUC, 2005. (Tese de doutorado).

Reis, Ramiro José dos. Operação Condor e o sequestro dos uruguaios nas ruas de um porto não muito alegre. Porto Alegre: UFRGS, 2012 (Tese de doutorado).

Teles, Janaina (org.) Mortos e desaparecidos políticos: reparação ou impunidade? São Paulo: Humanitas/ FFLECH/USP, 2001 (Seminário organizado em 1997).

\section{Sites}

\section{Censo sobre Educação relativo aos nomes de escola}

https://www.revistaforum.com.br/.../campanha-defende-substituicao-denomes-de-dia.../ Consulta em 1 de abril de 2014 
http://www.tonorumo.org.br/2014/04/campanha-defende-substituicao-denomes-de-ditadores-das-escolas/ Consulta em 4 de abril de 2014

https://www.pragmatismopolitico.com.br/.../nomes-de-ditadores-em-escolasdo-maran. Consulta em 3 abril 2015

https://noticias.r7.com/.../escolas-que-homenageiam-ditadores-passam-a-ternome-de-... Consulta em 1 de abril de 2015

https://oglobo.globo.com/sociedade/educacao/pais-tem-quase-mil-escolascom-nomes-de-presidentes-da-ditadura-9782672\#ixzz4sUYtd1c7/ Consulta em 3 de abril de 2015

www.vermelho.org.br/noticia/276087-1 Consulta em 3 de fevereiro de 2016

\section{Censura nas Universidades}

https://www.documentosrevelados.com.br/repressao/.../lei-477-o-ai5-dasuniversidades.../ Consulta em 1 de junho de 2012

https://oglobo.globo.com/brasil/reitoria-da-usp-contribuiu-com-espionagemna-ditadura-militar-aponta-documento-10072690/ Consulta em 20 de setembro de 2013

http://www.snh2015.anpuh.org/resources/anais/39/1457635923_ARQUIVO_ Dinorah_Rubim.pdf/Consulta em 10 abril maio 2015

http://www.scielo.br/scielo.php?script=sci_arttext\&pid=S2237101X2008000100030/ Consulta em 20 de agosto de2017

http://atom.ippdh.mercosur.int/index.php/universidade-de-brasiliaassessoria-de-seguranca-e-informacoes-unb-asi-universidade-debrasilia-assessoria-especial-de-seguranca-unb-aesi/ Consulta em 1 de setembro de 2017

www.niepmarx.blog.br/MM2017/anais2017/MC86/mc861.pdf/ Consulta em 10 de outubro de 2017

http://www.jornalbeiradorio.ufpa.br/novo/index.php/2014/151-2014-05-2017-42-48/1607-entrevista-a-universidade-no-tempo-da-ditadura Consulta em 10 de outubro de 2017 http://folha.uol.com.br/.../1538849-comissao-da-usp-lista-664perseguidos-pela-dita.../ Consulta em 11 de outubro de 2017 


\section{Desmonumentar/ Escrachos/ Intervenções}

https://noticias.r7.com/brasil/noticias/manifestantes-fazem-escracho-emfrente-a-casa-de-acusados-de-tortura-em-seis-estados-20120326.html/ Consulta em 26 de março de 2012

https://luizclaudiocsouza.wordpress.com/2012/070/ Consulta em 2 de abril de 2012

http://www.redebrasilatual.com.br/cidadania/2012/07/manifestantesescracham-estatua-de-castello-branco-no-rio Consulta em 30 de julho de 2012

www.anistiapolitica.org.br/abap/index.php?option=com_content\&view... Consulta em 3 de setembro de 2013

https://issuu.com/jornaldiariopopular/docs/01_04_2014_00_13_23 Consulta em 1 de abril de 2014

https://jornalistaslivres.org/2016/04/escracho-na-casa-do-vice-presidentemichel-temer/ Consulta em 17 de abril de 2016

http://jornalggn.com.br/noticia/jovens-fazem-ato-de-escracho-em-frente-acasa-de-temer/ Consulta em 21 de abril de 2016

https://www.opovo.com.br/jornal/.../2017/.../marco-zero-foi-arrancado-esoterrado.ht Consulta em 18 de julho de 2017.

https://pt-br.facebook.com/levantepopularPR/posts/620877784670482 Consulta em 11 de outubro de 2017

http://www.diariodoaco.com.br/ler_noticia.php?id=2505\&t=prefeitura-dedom-cavati-derruba-estatua-de-castello-branco/Consulta em 10 de outubro de 2017

http://outraspalavras.net/outrasmidias/.../castelo-branco-mais-um-escrachoa-ditadura/ Consulta em 13 de outubro de 2017

\section{Escolas alteram nome}

http://nucleopiratininga.org.br/racismo-e-ditadura-escolas-mudam-de-nomeno-brasil-e-nos-eua. Consulta em 23 dezembro de 2013

https://blogdomariomagalhaes.blogosfera.uol.com.br/.../apos-54-anos-escolados-eua-... Consulta em 23 de dezembro de 2013

http://g1.globo.com/.../escolas-do-ma-que-homenageavam-ditadores-temnomes-substituido Consulta em 1 de abril de 2013 
http://odia.ig.com.br/noticia/rio-de-janeiro/2014-02-22/a-cartografia-daditadura.html Consulta em 23 de fevereiro de 2014

https://www.cartacapital.com.br/blogs/parlatorio/escolas-do-maranhaotrocam-nomes-de-presidentes-da-ditadura-por-educadores-9263.html/ Consulta 18 setembro 2015

http://expressaosergipana.com.br/a-renomeacao-das-escolas-e-a-comissaoda-verdade-em-sergipe-e-possivel-e-necessario-ir-alem/ Consulta em 15 de janeiro de 2016.

http://ditaduranuncamais.cnte.org.br/escolas-que-homenageavam-politicosda-ditatura-tem-nomes-alterados/Consulta em 10 de abril de 2016

https://www.carosamigos.com.br/index.php/cotidiano/2367-salvador-colegiocastelo-branco-muda-nome-para-mandela/ Consulta em 25 de junho de 2016

http://www.correiobraziliense.com.br/app/noticia/euestudante/ensino_educacaobasica/2015/04/01/ensino_educacaobasica _interna,477871/governo-do-maranhao-altera-nome-de-escolas-quehomenageavam-ditadores.shtml Consulta em 25 de setembro de 2017

www.radioculturafoz.com.br/projeto-quer-alterar-nomes-de-ruas-de-foz-comreferen.... Consulta em 25 de setembro de 2017

www.tribunademinas.com.br/.../estudantes-querem-mudar-nomes-quehomenageiam-... Consulta em 15 de outubro de 2017

\section{Sobre filmes}

https://7artelatina.wordpress.com/2015/08/12/10-filmes-para-entender-asditaduras-latino-americanas-dos-anos-1970/Consulta 10 de dezembro de 2012

https://catracalivre.com.br/geral/tecnologia/indicacao/8-filmes-que-ajudama-entender-a-ditadura-militar/ Consulta em 16 de março de 2015

http://www.planetaamericalatina.com.br/artigo/olvidados-filme-boliviano-eindicado-ao-oscar-2015. Consulta em 10 de outubro de 2015

http://www.cinemafuria.com.br/2017/02/15-filmes-para-compreenderditadura.html/ Consulta em 3 fevereiro de 2017 